\title{
COMMENTARY
}

\section{The race of patients and physicians can affect the quality of health care provision}

Ellen and colleagues' study indicates a low screening rate for a high-risk population. These findings are alarming because the need for consistent screening of adolescents has been repeatedly established.

One study of inner-city adolescent females concluded that they should be screened for chlamydia every 6 months, based on the incidence of this infection in the study population. ${ }^{1}$ Another study also suggests an optimal screening interval of 6 months, based on high STD prevalence and incidence despite moderate risk behavior, such as only 1 lifetime sexual partner. ${ }^{2}$

Ellen and associates found a low rate of STD screening even among adolescents attending for primary care visits. This is consistent with other reports of poor rates of screening and delivery of preventive services to adolescents in a variety of clinical settings, including primary care visits. $^{3,4}$

As health care physicians for a substantial African American population in the Adolescent Medicine clinic of Children's Hospital, Oakland, California, we believe that a major barrier to adequate STD education and screening in adolescents is physicians' failure to discuss sexuality. This failure occurs despite well-documented guidelines, such as the American Medical Association's Guidelines for Adolescent Preventive Services (GAPS), and screening and assessment tools, such as the "HEADS" psychosocial assessment-home environment, education, activities and employment, peer activities, drugs, sexuality, and suicide. ${ }^{5}$ A recent study of California primary care providers showed that less than $40 \%$ of physicians asked all of their adolescent patients about sexual activity. ${ }^{3}$ Appropriate STD screening cannot be performed without taking an adequate sexual history. The preventive primary care visit is just 1 of many opportunities to obtain sexual histories and perform appropriate screening. The philosophy at our clinic is to use every visit as an opportunity to discuss issues related to sexuality and to screen for STDs, if indicated. This requires flexibility in the physician's schedule because a visit for a minor respiratory tract infection might turn into a lengthier STD screening.

In the African American population studied by Ellen and colleagues, there may have been inherent barriers to the delivery of primary health care services. As a group composed primarily of African American health care providers, we find it interesting that the authors did not comment on the role that race itself may have had in determining health care access and delivery, despite the fact that the study focused exclusively on African American adolescents. Race may have been a major barrier to the delivery of primary care services to the study population. The race of patients and providers affects quality of care, access to care, health care service provision, and screening. ${ }^{6-8}$ Provider attributes, including race, can undoubtedly influence patients' use of health care. Black patients are more likely to report having received preventive and other medical care, and to rate their physician as excellent, if their physician is also black. ${ }^{8}$ There is increasing evidence of the importance of such racial concordance in ensuring access to and continuation of health care. ${ }^{9}$ It is reasonable to assume that screening rates for African American adolescents might have been higher if they had been given access to African American providers. At the very least, the issue of racial concordance and discordance should have been explored and discussed.

In another article in the same study population, it was reported that African American teens placed the greatest importance on provider attributes when deciding to seek STD care. Provider attributes did not include race but
Barbara Staggers D’Juanna White Roberto Rodriguez Adolescent Medicine Clinic 747 52nd St Oakland, CA 94609

Children's Hospital Oakland, CA

Correspondence to: Dr Staggers

Bstaggers@mail.cho.org

Competing interests: None declared.

West J Med 2000;173:113-114 
focused on those characterized primarily as behavior. ${ }^{10,11}$ It is critical to explore the effect of provider race as one of the provider attributes. We encourage health care professionals to consider these issues when caring for adolescent patients.

References

1 Burstein GR, Gaydos CA, Diener-West M, Howell MR, Zenilman JM, Quinn TC. Incident Chlamydia trachomatis infections among inner-city adolescent females. JAMA 1998;280:521-526.

2 Bunnell RE, Dahlberg L, Rolfs R, et al. High prevalence and incidence of sexually transmitted diseases in urban adolescent females despite moderate risk behaviors. J Infect Dis 1999;180:1624-1631.

3 Millstein SG, Igra V, Gans J. Delivery of STD/HIV preventive services to adolescents by primary care physicians. J Adolesc Health 1996;19:249-257.
4 Ellen JM, Franzgrote M, Irwin CE Jr, Millstein SG. Primary care physicians' screening of aadolescent patients: a survey of California physicians. J Adolesc Health 1998;22:433-438.

5 Goldenring JM, Cohen E. Getting into adolescent heads. Contemp Pediatr 1988;5:74-90.

6 Geiger HJ. Race and health care: an American dilemma? N Engl J Med 1997; 12:267-273

7 Shi L. Experience of primary care by racial and ethnic groups in the United States. Med Care 1999;37:1068-1077.

8 Saha S, Komaromy M, Koepsell TD, Bindman AB. Patient-physician racial concordance and the perceived quality and use of health care. Arch Intern Med 1999;159:997-1004.

9 Cooper-Patrick L, Gallo JJ, Gonzalez JJ, et al. Race, gender, and partnership in the patient-physician relationship. JAMA 1999;282:583-589.

10 Freed LH, Ellen JM, Irwin CE Jr, Millstein SG. Determinants of adolescents' satisfaction with health care providers and intentions to keep follow-up appointments. J Adolesc Health 1998;22:475-479.

11 Lane MA, McCright J, Garrett K, Millstein SG, Bolan G, Ellen JM. Features of sexually transmitted disease services important to African American adolescents. Arch Pediatr Adolesc Med 1999;153:829-833.

\section{A Book That Changed Me}

\section{Understanding today's Joads: revisiting The Grapes of Wrath by John Steinbeck}

Like all great books, Steinbeck's The Grapes of Wrath absorbs and entertains but also alters our perspective on life. Its principal theme is intolerance, its uncomfortable lesson is that prejudice lies beneath the surface of us all, but its optimistic conclusion is the courage of the human spirit and the kernel of good that remains when all else is stripped away. The poetic style and vernacular dialogue take time at first, but once it hooks the reader, it won't let go.

It is the story of the Joad family-Oklahoma farmers whose lives are ruined by the Dust Bowl of the 1930s. Forced from their land and fueled by their belief in the "American dream" of opportunity, they travel west to California. They endure dreadful hardship on the way, and when they arrive, their optimistic hopes and dreams are shattered by the hostility they encounter.

Steinbeck's greatest skill is showing how the Joads engender this hostility, prickling our own innate prejudices. They are crude, crassly naive, violent, and hypocritical. They seem unable to make the link that they are being driven from the land as their forefathers drove the native Indians from it. Yet, once the reader gets to know them, feel the pathos of their humanity, and share their experience, it is impossible not to become deeply attached and then appalled not only at the treatment they receive but also at our own initial prejudicial reaction.

I have just reread the book after 20 years, and its relevance persists. The homeless, travelers in their caravans, asylum seekers, and refugees are all today's Joads.

Throughout the novel, Steinbeck parodies faith that has no moral depth. He uses many biblical themes and images, and some passages of the book are written in a quasi-scriptural tone. The Bible developed out of a collective human need to give life context, meaning, and a moral structure, but Steinbeck suggests that this message, along with its contemporary relevance, has been lost. In a secular, multicultural age, The Grapes of Wrath shows that storytelling remains (next to life itself) the preeminent form to teach us about ourselves and our world. It is a book that teaches empathy, compassion, and tolerance. But perhaps its greatest lesson is that these things need to be taught, and constantly retaught, to us all.

Simon Curtis

Summertown Health Centre

160 Banbury Rd

Oxford, England 